\title{
Learning to be Affected in Contemporary Art
}

\section{Stephanie Springgay, University of Toronto}

The Canadian artist Diane Borsato has explored a number of different projects with bees and beekeepers, mushrooms and mychologists, and with plants. Much of Borsato's practice is concerned with 'learning' through affective, bodily, and intimate gestures. She often works with specific groups of people - mycologists, astronomers, physicists, tea sommeliers, ikebana practitioners and beekeepers - in order to think about the mobility of thought, about ethical-political encounters, and the affective dimensions to embodied knowing. One of her earlier projects with bees, Italian Lessons (2007-2011), involved an apprenticeship of sorts in beekeeping in Zafferana Etnea, Italy a town populated by more than 700 beekeepers. Borsato, unfamiliar with the local Italian dialect, worked intimately and patiently with a beekeeper learning Italian and beekeeping simultaneously.

In Your Temper My Weather Borsato worked with 100 beekeepers from the Ontario region. In a five-hour performance in the Walker Court at the Art Gallery of Ontario, Canada, Borsato and the beekeepers meditated. Beekeepers often describe the effects of beekeeping as similar to meditation, noting states of calm, focus, mindfulness, attunement, and rhythm. Similarly, many beekeepers meditate, read books, write, or do other quiet and intimate activities alongside or in very close proximity to their hives, communing with the bees as they fly in and out of the hive. For Borsato and other beekeepers this meditation entangles the rhythm of bees with human mindfulness, suggesting a connectivity between human and non-human elements. These issues were 
expanded on in her Apiary Videos, which depict beekeepers meditating in eight different regional apiaries from backyards, rooftops, botanic gardens and industrial wastelands in an attempt to alter environmental conditions that affect bees, humans, and the earth.

Another project of Borsato's that I think extends the questions and problems regarding ecologies are the works that she has done with mychologists. Her work with mushrooms and mycelium, and her collaborations with amateur mychologists, speak to movements' virtuality. In the 2008 China Town Foray, which has had a number of iterations, Borsato leads a mushroom foray through urban streets, with a particular focus on a city's Chinatown, where variations of mushroom species can be found in shops (Springgay 2012). In another fungi project Terrestrial/Celestial from 2010, amateur mychologists and astronomers were brought together for a day-long event in which they shared their field knowledge. While bees elicit fear from stings and swarms, and feature spectacularly in public imaginations about environmental degradation and collapse, mushrooms are often vilified for being passive, inactive, and immobile. Fungi are found on forest floors, decaying logs, and while they signify the earth's heterogeneous renewal they are often marked as dirty and worthless. Yet fungi — of which mushrooms are only the fruiting part - coexist in complex ecosystems with other plants. Moreover, within this vitality is a rhythm of movement too subtle for human perception, a virtual movement.

My research into Borsato's various projects is to think about an affective pedagogy, which proposes to intervene in ecologies of human and nonhuman relations. Rather than understanding her work simply as enacting embodied and experiential learning, thereby reducing it to both a human construct and a human experience, I am interested in the ways her interventionist gestures transform pedagogy from learning 'about' to the mobility of thinking-doing, which demands that the boundaries between human and non-human become viscous.

For example, her projects do not set out to measure how much Italian is learned or the nature of that learning, or what species of mushrooms are identified; rather the incipiency of learning, of becoming more-than with the earth, are the gestures she invites. My contention is that Borsato's work can push us beyond the experience of art, where experience is understood as resemblance, towards an affective pedagogy of movement, where movement between bees, bee keepers, hives, galleries, and so on 
constitutes a multiplicity, where all the elements are connected to and implicated in what comes to be constituted through the composition.

In her most recent work Borsato has been studying Ikebana flower arrangements, which she composes using found fruits and vegetables in her fridge, or more recently from objects and leftover materials from museum installations and receptions in the Museum of Contemporary Canadian Art in Toronto. The Sogetsu-style arrangements, composed from disparate natural and artificial materials playfully collides matter emphasizing the autonomy of objects and their more-than relation to human knowing. Here matter is distributed across a swarm of various vibrant multiplicities opening creative possibilities and providing a powerful alternative to thinking an affective pedagogy as movement.

\section{Reference List}

Springgay, S. (2012) “"The Chinatown Foray” as Sensational Pedagogies,' Curriculum Inquiry, vol. 41, no. 5: 636-656. doi: http://dx.doi.org/10.1111/j.1467-873X.2011.00565.x.

\section{Images: The Chinatown Foray}

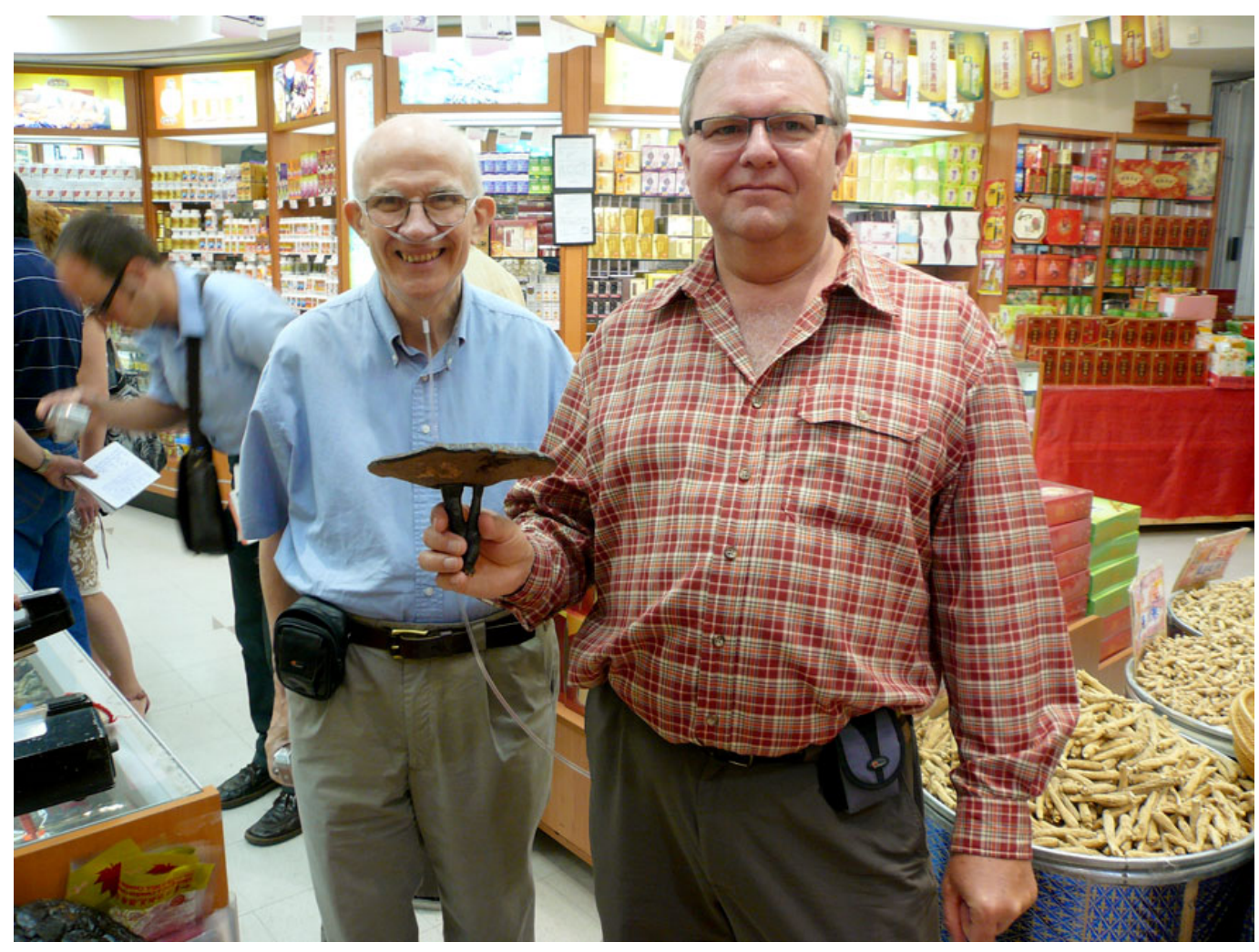

Figure 1: The Chinatown Foray, Intervention and project documentation digital photograph, Toronto and New York City, 2008-2010,

Diane Borsato: http://dianeborsato.net/projects/the-chinatown-foray/. 

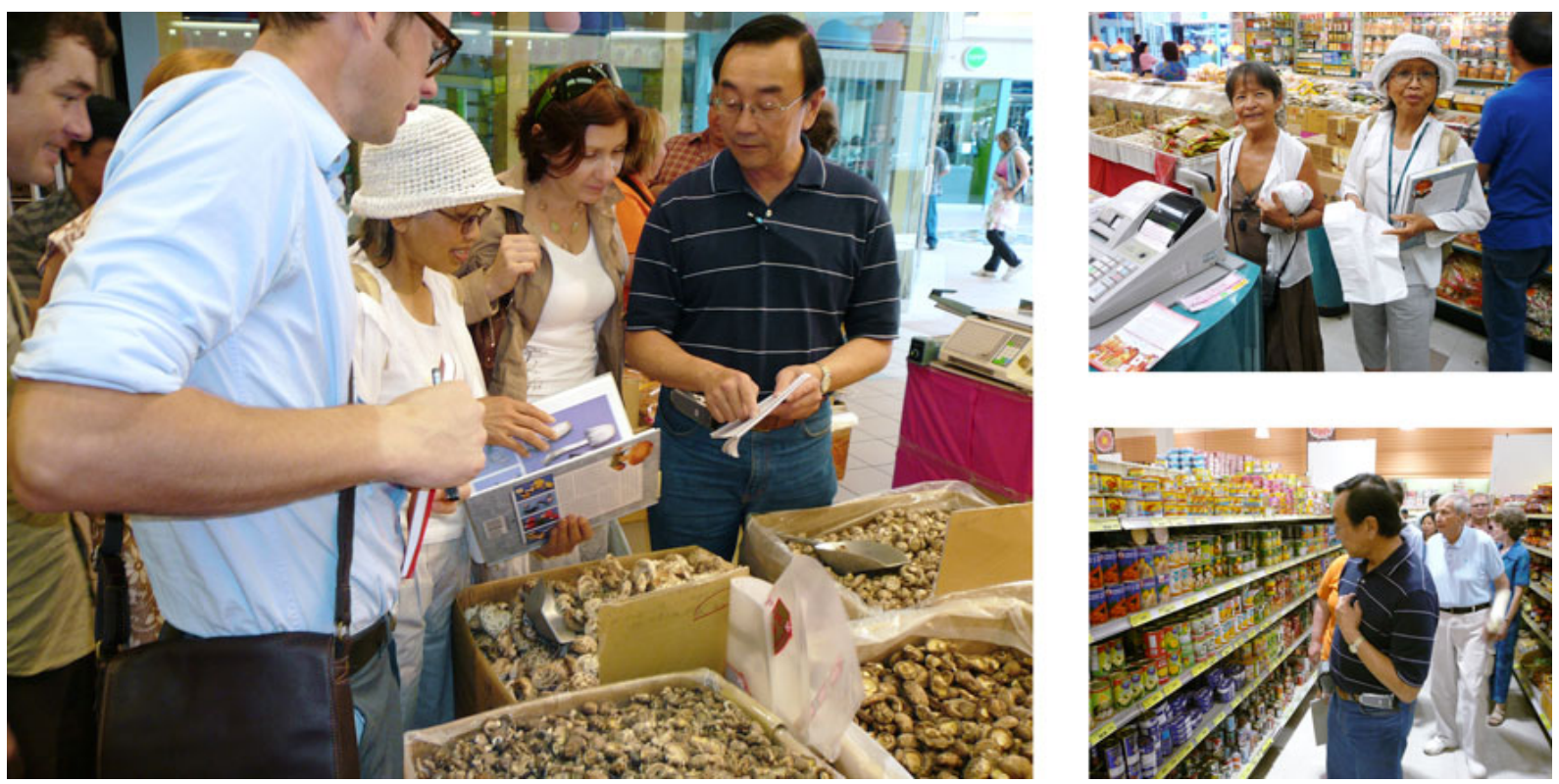

Figure 2: The Chinatown Foray, Intervention and project documentation digital photographs, Toronto and New York City, 2008-2010,

Diane Borsato: http://dianeborsato.net/projects/the-chinatown-foray/.

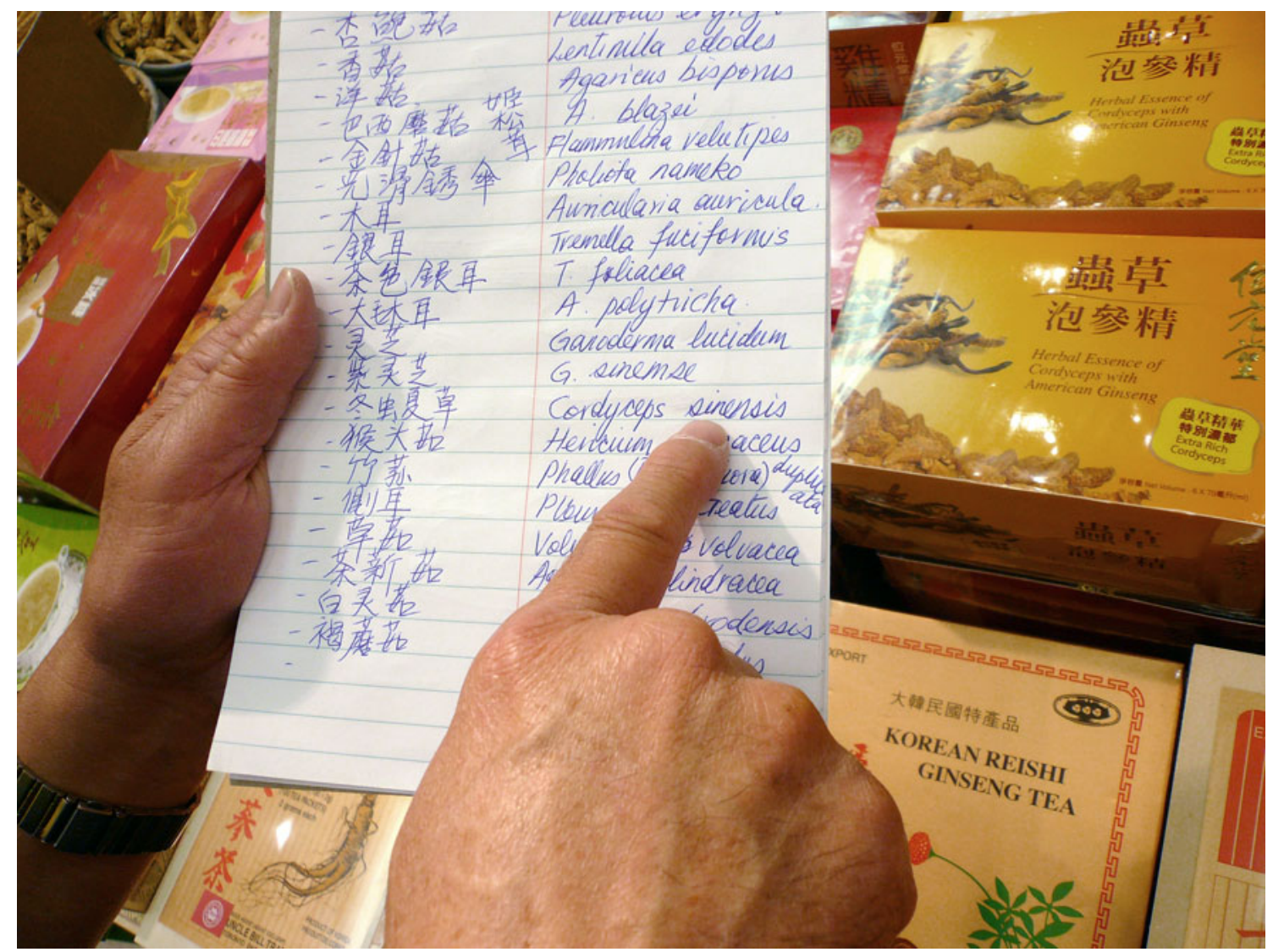

Figure 3: The Chinatown Foray, Intervention and project documentation digital photograph, Toronto and New York City, 2008-2010,

Diane Borsato: http://dianeborsato.net/projects/the-chinatown-foray/. 


\section{Images: Terrestrial/Celestial}

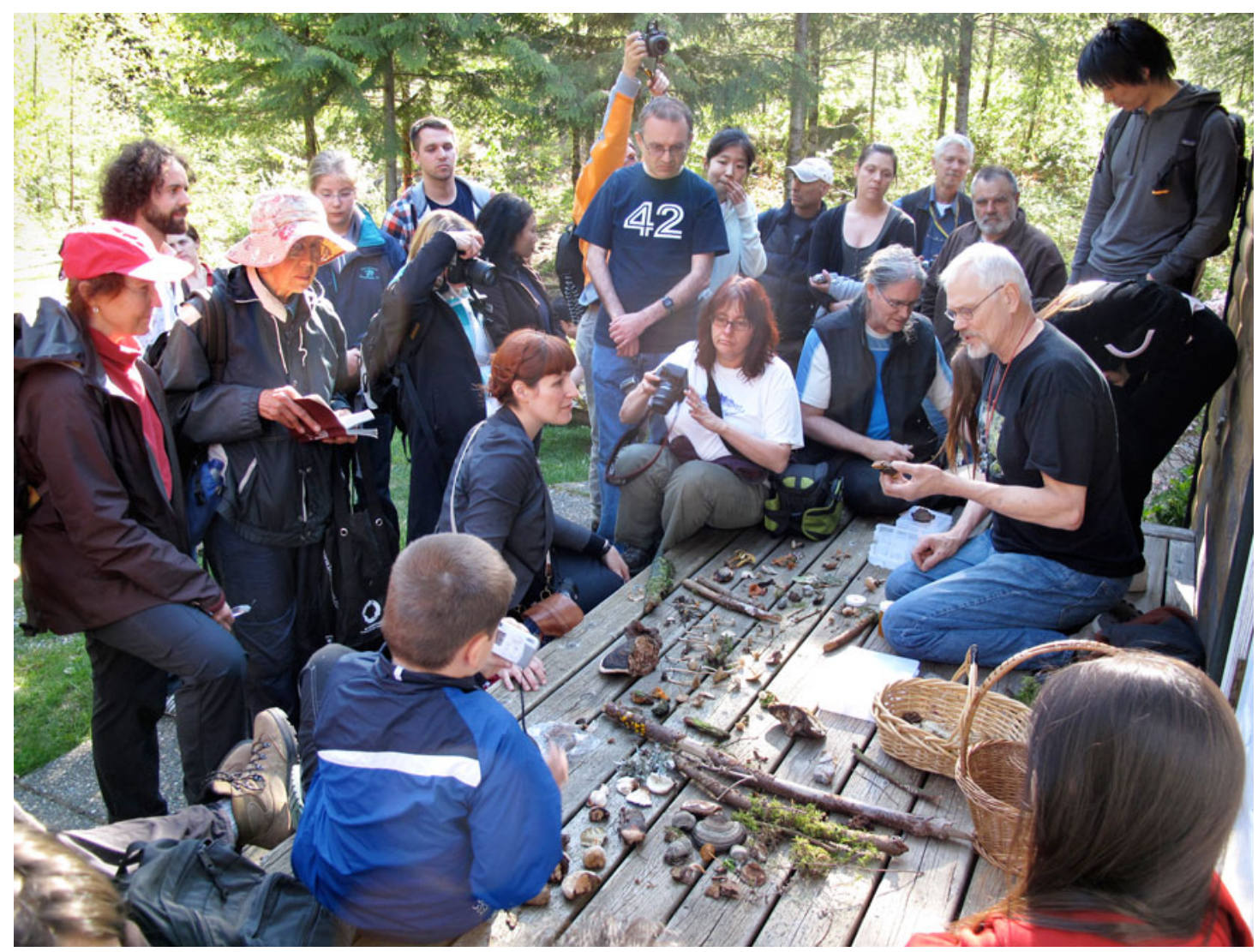

Figure 4: Terrestrial/ Celestial, Relational performance and project documentation digital photograph, Toronto and Vancouver region, 2009-2010,

Diane Borsato: http://dianeborsato.net/projects/terrestrial-celestial/.
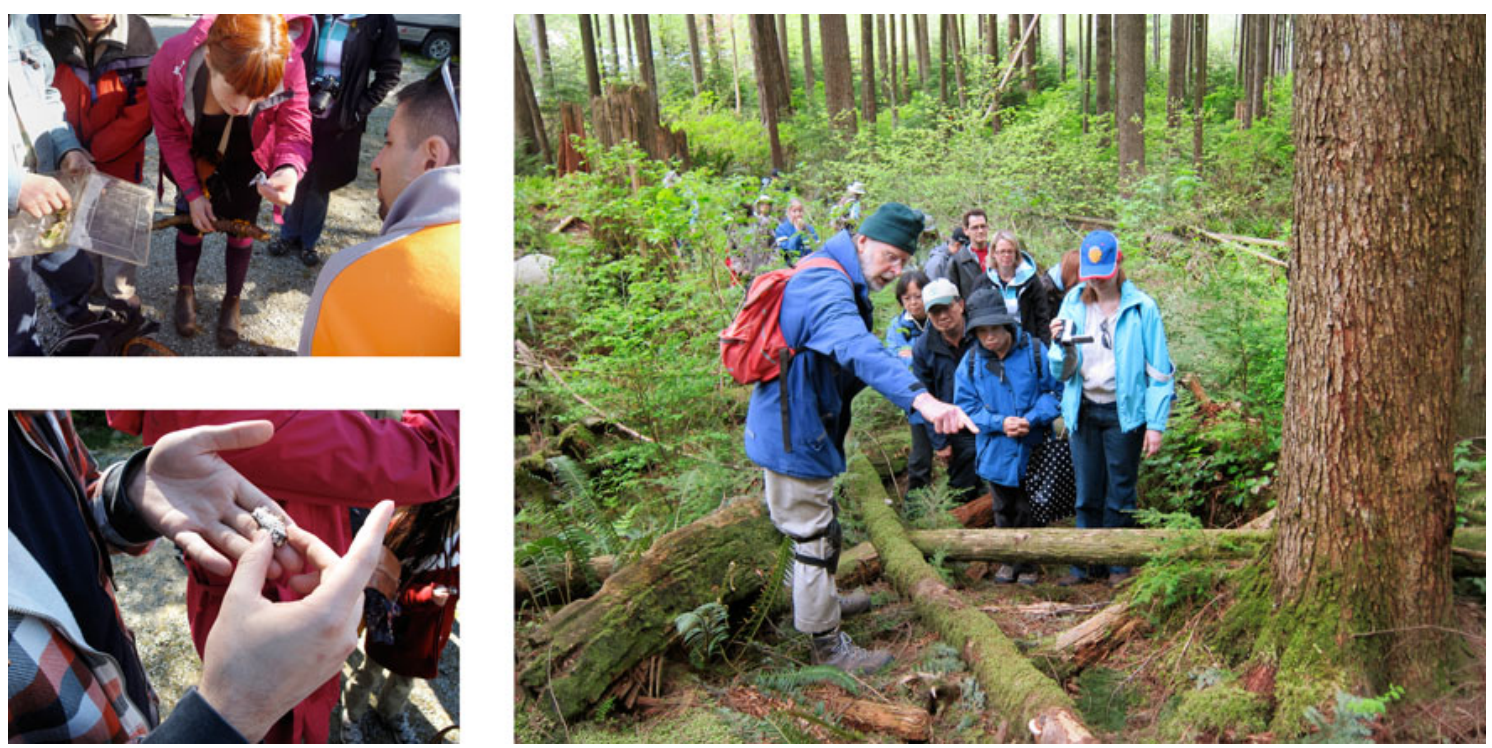

Figure 5: Terrestrial/ Celestial, Relational performance and project documentation digital photographs, Toronto and Vancouver region, 2009-2010,

Diane Borsato: http://dianeborsato.net/projects/terrestrial-celestial/. 

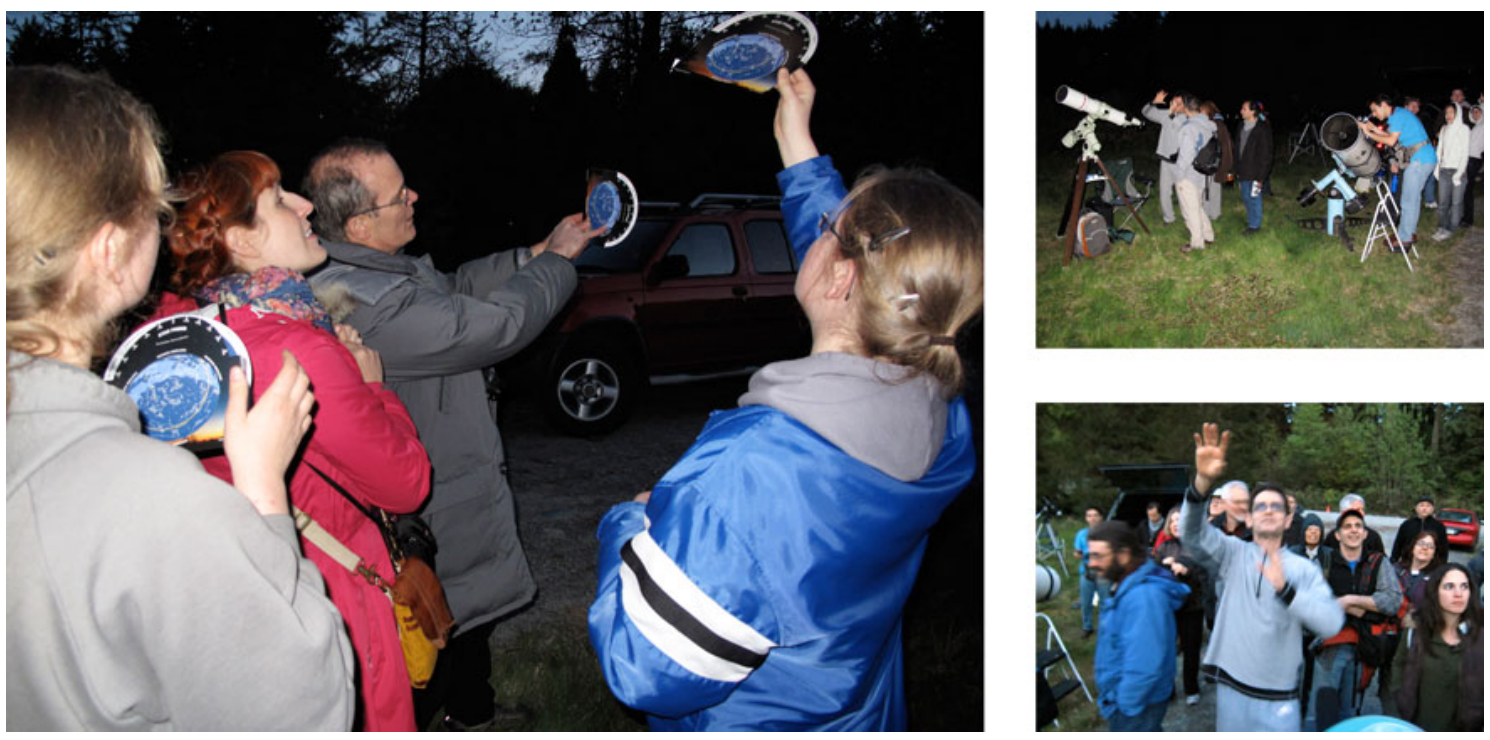

Figure 6: Terrestrial/ Celestial, Relational performance and project documentation digital photographs, Toronto and Vancouver region, 2009-2010,

Diane Borsato: http://dianeborsato.net/projects/terrestrial-celestial/. 